\title{
Analyzing Energy Efficiency Factors of Residential Towers using fuzzy AHP: A case from India
}

\author{
S.S.Qarnain, S. Muthuvel, S. Bathrinath
}

\begin{abstract}
Increasing population, rising cost of energy bills and non-availability of housing land in cities has necessitated the need to build high rise residential towers for living purposes. As these towers are operational throughout the year, the energy consumed for maintenance and operation of such buildings is huge. Attaining building energy efficiency is a significant step towards conserving energy and minimizing the cost of utility bills. To achieve this factors that lead to energy efficient operations and maintenance of the residential towers must be found and prioritized. This research work is one such case study conducted on residential towers in South India, to find the energy efficiency factors in a building and prioritizing them according to their relative importance. The results showed that Building energy administration, energy Audits and Building Automation system are among the top factors that can highly influence the energy consumption pattern in a building. The Analysis is conducted using fuzzy AHP methodology and validated through sensitivity analysis. Further the paper also discusses the results and provides managerial application as a roadmap for energy efficiency in buildings.
\end{abstract}

Keywords: AHP, Energy efficiency, Residential tower.

\section{INTRODUCTION}

Residential energy consumption in India is estimated about 238 billion $\mathrm{kWh}$ in 2015-2016 [1] India was the third largest consumer of energy in the world after U.S and China in 2013. [2], and almost $25 \%$ of the energy is consumed by Residential Sector in India [3]. Fig 1 shows that the domestic residential sector consumes one fourth of the energy produced. The energy demand from Residential sector has grown more than 50 times from 1971 and will continue to grow rapidly due to rapid electrification, Govt policies, increase in household income and technological advancement. [4]. To keep up the balance of energy demand and supply it is necessary that the residential sector in urban localities should follow energy efficient practices. In major cities and urban neighborhoods residential towers are new trend because they require less foot print and provide more floor space. Along with many benefits the residential towers offer they come along with more energy intensity consuming more energy for small area of building footprint.

Revised Manuscript Received on December 30, 2019.

* Correspondence Author

S.S.Qarnain, Department of mechancical engineering, Kalasalingam Academy of research and education, Krishnankoil-626126, India. Email: drqarnain@gmail.com

S.Muthuvel, Department of mechancical engineering, Kalasalingam Academy of research and education, Krishnankoil-626126, India. Email: bathri@gmail.com

S.Bathrinath*, Department of mechancical engineering, Kalasalingam Academy of research and education, Krishnankoil-626126, India. Email: ssaravanasankar@klu.ac.in
For the practical estimation of the future energy demand, the cognizance of energy consumption pattern of residential towers and their factors is extremely essential

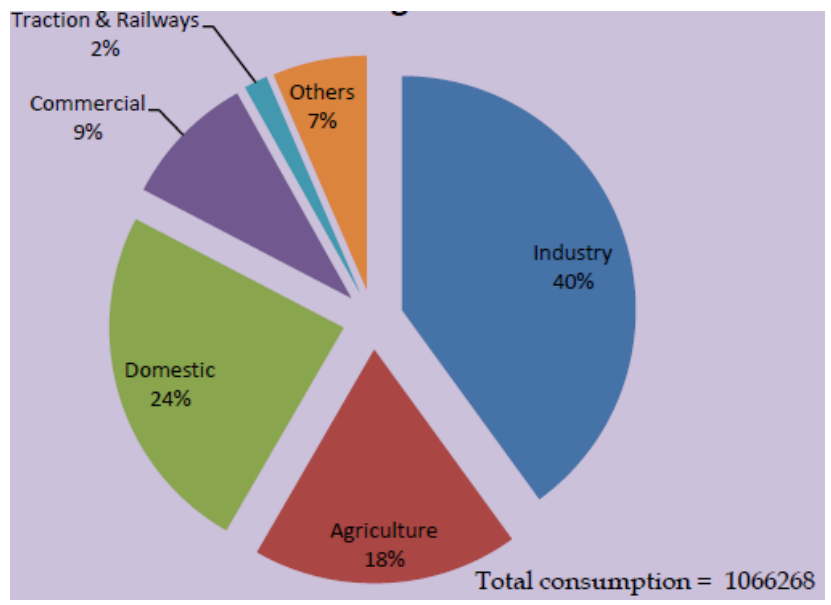

Fig. 1. Energy statistics 2018

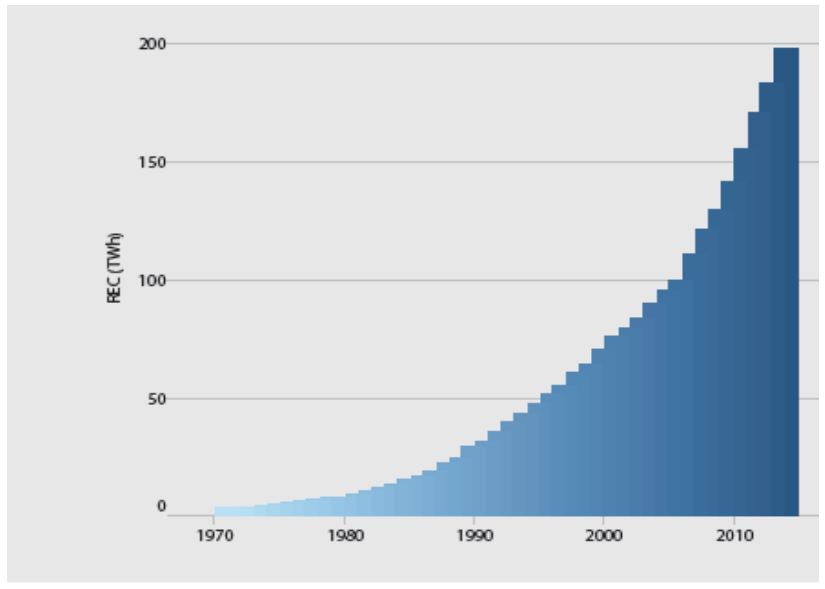

Source: (MOSPI, 2015), (CEA, 2011), (CEA, 2014) and older Annual General Reviews by CEA

Fig. 2. Residential electricity consumption in India

Fig 2 shows the electricity consumption pattern his raised exponentially from 1970. From fig 1 and from fig 2 it is evident that residential sector consumes a major portion of energy produced. Therefore, energy efficiency and energy conservation of residential towers and factors affecting them should be analyzed. This research work is an attempt to bring in energy efficiency in Residential towers by analyzing the factors effecting energy consumption of residential towers in southern India. 


\section{Analyzing Energy Efficiency Factors of Residential Towers using fuzzy AHP: A case from India}

Energy consumption by residential sector will rise by eight times by 2050 , therefore it is essential that India develops strategies for efficient consumption of energy in residential sector to balance energy demand [5].

In India the residential sector constitutes about $79.9 \%$ of the housing buildings and consumes about $21.98 \%$ of the total energy produced. Residential sector is the second highest energy consuming sector after Industry. The per capita residential energy consumption is 0.63 Mwh which is third highest after China and U.S [6] From Fig 3 it is evident that Energy saving potential is more than one third for domestic residential sector.

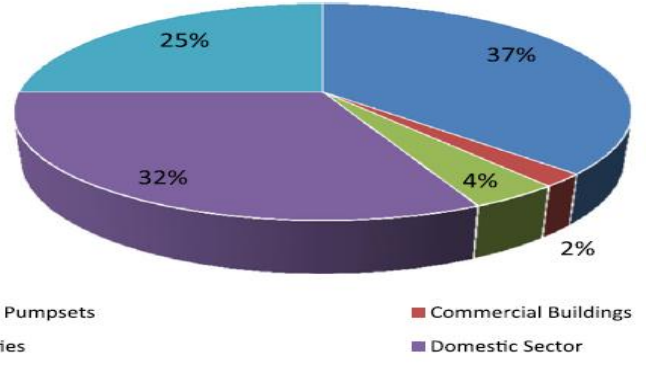
- Municipalities
Domestic Secto

- Small \& Medium Enterprises and Large Industrie

Fig. 3. Indian scenario. Energy saving potential sectorial [1]

The energy consumption from countries like India has direct effect on Global GHG emissions effecting world environment. India is among the top ten countries contributing to $\mathrm{CO}_{2}$ Emissions and Residential Consumption of energy is one among the causes for $\mathrm{CO}_{2}$ Emissions. Residential Sector is the single largest sector that exceeded demand to about $23 \%$ between 2000 to 2011. [2]

\section{METHODOLOGY}

Fuzzy set theory was developed by T.L Saaty in 1970's, it is a technique where subjective and objective functionalities can be included with dynamic participation of subject experts and it can solve problems relatively. In Fuzzy set theory a hierarchy decision model is framed by decomposing the problem into main problem and sub branches. The judgements are compared pairwise with criteria preceding them in the hierarchy.

The methodology for Fuzzy AHP is as follows: -

Step 1. Construct the pairwise comparison Criteria matrix as shown in equation 1 with the input from Experts survey using the Fuzzy Scale as given in Table 1.

$$
A=\left[\begin{array}{cccc}
a_{11} & a_{12} & \ldots & a_{1 n} \\
a_{21} & a_{22} & \ldots & a_{2 n} \\
\ldots & \ldots & \ldots & \ldots \\
a_{n 1} & a_{n 2} & \ldots & a_{n n}
\end{array}\right]
$$

Table- I. Influence scale

\begin{tabular}{|l|l|l|l|}
\hline \multicolumn{2}{|l|}{} & Fuzzy Scale & $\begin{array}{l}\text { Inverse fuzzy } \\
\text { Scale }\end{array}$ \\
\hline Equal & 1 & $1,1,1$ & $1,1,1$ \\
\hline Influential & 2 & $1 / 2,1,3 / 2$ & $2 / 3,1,2$ \\
\hline Weak & 3 & $1,3 / 2,2$ & $1 / 2,2 / 3,1$ \\
\hline Strong & 4 & $3 / 2,2,5 / 2$ & $2 / 5,1 / 2,2 / 3$ \\
\hline Very strong & 5 & $2,5 / 2,3$ & $1 / 3,2 / 5,1 / 2$ \\
\hline Absolute strong & 6 & $5 / 2,3,7 / 2$ & $2 / 7,1 / 3,2 / 5$ \\
\hline
\end{tabular}

Step 2. Normalize the Criteria Matrix by dividing each element in the column by its total sum of the column as given by Equation 2 .

$$
\begin{array}{r}
A=\left[\begin{array}{cccc}
a_{11}^{r} & a_{12}^{r} & \ldots & a_{1 n}^{r} \\
a_{21}^{r} & a_{22}^{r} & \ldots & a_{2 n}^{r} \\
\ldots & \ldots & \ldots & \ldots \\
a_{n 1}^{r} & a_{n 2}^{r} & \ldots & a_{n n}^{r}
\end{array}\right] \\
\text { and } a_{i j}^{r}=\frac{a_{i j}}{\sum_{1=n}^{2} a_{i j}} \text { for } \mathrm{i}, \mathrm{j}=1,2,3 \ldots \mathrm{n}
\end{array}
$$

Step 3. Obtain the local weight of each factor: This is obtained by taking the average sum of each row from the normalized matrix as shown in equation 3 .

$$
\text { Local Weight }=\frac{\sum_{i=1}^{n} a_{i j}}{n}
$$

Step 4. Obtain the Normalized matrix and local weight for each sub criteria matrix

Step 5. Multiply the Local Weight of each sub criteria with the Local Weight of its own Main criteria to arrive at Global Weight of each Factor.

Step 6. Rank the Global weight to arrive at the most influencing factor.

\section{APPLICATION OF THE PROPOSED MODEL TO THE CASE ILLUSTRATION}

To arrive at the factors that can impact the energy consumption of residential towers, Energy managers of fifteen residential towers were consulted, ten out of fifteen agreed to provide input in the form of reply to questionnaire. These managers were possessing more than twelve years of experience in Maintenance, Operation, Retrofitting and formation of energy policies of the respective residential towers. Among the ten energy managers eight were graduates and two were post graduates in Energy related field. They were also actively involved in energy administration,

\begin{tabular}{|c|c|c|}
\hline & Main Factors & Subfactors \\
\hline 1 & \multirow{2}{*}{$\begin{array}{c}\text { Building Energy } \\
\text { Administration. (BEA) }\end{array}$} & Energy Audits \\
\hline 2 & & Building Automation System \\
\hline 3 & \multirow{3}{*}{ Energy Policy (EP) } & Mgmt. policy \\
\hline 4 & & Tenant Policy \\
\hline 5 & & Regulatory Compliance \\
\hline 6 & \multirow{3}{*}{$\begin{array}{c}\text { Education and } \\
\text { Awareness (EAW) }\end{array}$} & Guest Education \\
\hline 7 & & Tenant Education \\
\hline 8 & & Employee education \\
\hline 9 & \multirow{4}{*}{$\begin{array}{l}\text { Feedback and Continual } \\
\text { improvement (FC) }\end{array}$} & Weekly Energy Meetings \\
\hline 10 & & Tenant Feedback Survey \\
\hline 11 & & Guest Feedback Survey \\
\hline 12 & & Suggestion Box \\
\hline & $\begin{array}{l}\text { Published By: } \\
\text { Blue Eyes Intelligence En } \\
\text { \& Sciences Publication }\end{array}$ & \\
\hline
\end{tabular}
management of buildings. The energy efficiency factors that were arrived at are listed in Table 2.

Table- II. Risk factors 
Step 1. The input from the energy managers is averaged to arrive at the criteria matrix. The Crisp numbers are converted into fuzzy scale given in Table 1. The Criteria Matrix for Main factors and similar Criteria Matrices for Sub Factors are calculated by using the equation 1 .

Step 2. Every element of a column in a matrix is divided by its respective sum of the column to obtain respective weight of the factor. The normalized matrices for Main Factors and for sub factors are calculated by using the equation 2 .

Step 3. The average sum of each row from the normalized matrix gives the local weight for each factor.

Step 4. The weight for Main Factors is given in Table 3. And The local Weight of each factor is provided in Table 4 by using the equation 3 .

Step 5. The global weight of each factor can be obtained by multiplying the local weight of each subfactor with its respective

\section{RESULT AND DISCUSSIONS}

The ranking order of the main factors are F1>F4 $>$ F3 $>$ F4 i.e. Building energy administration (BEA) has gained more weightage among all the main factors. It is due to the fact that the energy economics and cost of energy is dependent upon how the energy is administered inside buildings. Good energy administration in residential buildings brings in more cost benefits hence more attractive for adoption by energy managers. [3]

The second most Important factor is Feedback and continual improvement (FC) that has attained a weightage of 0.231 . The effectiveness of energy administration in a residential building depends upon the effective implementation and acceptance from the end users of the energy. In this research case the building occupants are the end users and their feedback of energy administration system and its effectiveness depends upon there feedback. upon receiving the feedback, the information is used for continual improvement of the building energy administration system.

The third highest weightage is attained by the main factor education and awareness (EAW) with a weightage of 0.202. The behavior and efficient usage of energy in homes depends upon how informed the residents of the building are. The energy conserving habits in young generation is inculcated by education and awareness [4]. In the residential towers that had been analyzed here have used placards and sign boards with pictographic contents to educate and create awareness among the residents of the tower.

The last factor that in the rank is Energy policy (EP). With a weightage of 0.1825 . This due to the fact that energy policies are made holistically considering the entire system. The Effect of energy policies bear fruitful results on a larger scale whereas the residential tower considered here are family dwelling units.

Table- III. Weight for main factors

\begin{tabular}{|l|l|l|l|}
\hline Factor No & Main Factor & Weight & Rank \\
\hline F1 & BEA & 0.3842 & 1 \\
\hline F2 & EP & 0.1825 & 4 \\
\hline F3 & EAW & 0.202 & 3 \\
\hline F4 & FC & 0.2312 & 2 \\
\hline
\end{tabular}

The order of ranking for subfactors is BEA1 $>$ BEA2 $>$ EAW $1>$ FC1 $>$ EP1 $>$ EAW2 $>$ EP2 $>$ FC4 $>$ FC2 $>$ EP $3>$ FC $3>$ E AW3. Table 14 shows the global ranking of all subfactors. The highest rank among all subfactor is Energy Audits (BEA1). Because energy Audits are one of the efficient tools to overcome the energy efficiency gap in buildings, Energy audits can identify the shortcoming in current energy administration system and correct the irregularities [5]. The subfactor Building Automation System (EAW2) is the second top subfactor. Because most of the service operational in energy systems can be made more efficient using Building Automation and administering building automation system does not require any behavioral changes from the occupants of the building [6]. The third highest Subfactor is obtained by subfactor Guest Education (EAW1) with a weightage 0.095 . The building is visited by many outsiders and guests in residential apartments and educating these outsiders about energy efficiency measures would definitely bear an impact on the energy services of the building.

The fourth highest impact is through subfactor Weekly energy meetings (FC1). These energy meetings act as a platform to discuss the practical issues encountered by the maintenance and operational staff with end-users. These energy meetings can be used to troubleshoot the problems that arise during implementing energy efficiency measure and act as platform to set energy benchmarks. EP1 i.e. energy management policy has attained fifth rank in the table 14 . The residential tower to control and monitor energy usage should have an energy policy in action such as switch off external lights between $5.00 \mathrm{am}$ to $5.00 \mathrm{Pm}$. such policies bear to have a fruitful result in effective conservation of energy in residential buildings.

\begin{tabular}{|c|c|c|c|c|c|}
\hline $\begin{array}{l}\text { Main } \\
\text { factor }\end{array}$ & $\begin{array}{c}\text { Sub } \\
\text { factor }\end{array}$ & $\begin{array}{c}\text { Local } \\
\text { Weight }\end{array}$ & $\begin{array}{c}\text { Local } \\
\text { rank }\end{array}$ & $\begin{array}{l}\text { Global } \\
\text { weight }\end{array}$ & $\begin{array}{c}\text { Global } \\
\text { rank }\end{array}$ \\
\hline \multirow{2}{*}{$\begin{array}{l}\text { BEA } \\
\text { Rank1) } \\
\end{array}$} & BEA1 & 0.71 & 1 & 0.273 & 1 \\
\hline & BEA2 & 0.29 & 2 & 0.111 & 2 \\
\hline \multirow{3}{*}{$\begin{array}{c}\text { EP } \\
(\text { Rank 2) }\end{array}$} & EP1 & 0.479 & 1 & 0.087 & 5 \\
\hline & EP2 & 0.268 & 2 & 0.049 & 7 \\
\hline & EP3 & 0.253 & 3 & 0.046 & 10 \\
\hline \multirow{3}{*}{$\begin{array}{c}\text { EAW } \\
\text { (Rank 3) }\end{array}$} & EAW1 & 0.469 & 1 & 0.095 & 3 \\
\hline & EAW2 & 0.317 & 2 & 0.064 & 6 \\
\hline & EAW3 & 0.214 & 3 & 0.043 & 12 \\
\hline \multirow{4}{*}{$\begin{array}{c}\mathrm{FC} \\
(\operatorname{Rank} 4)\end{array}$} & $\mathrm{FC} 1$ & 0.4 & 1 & 0.093 & 4 \\
\hline & $\mathrm{FC} 2$ & 0.2 & 3 & 0.046 & 9 \\
\hline & FC3 & 0.192 & 4 & 0.045 & 11 \\
\hline & $\mathrm{FC} 4$ & 0.207 & 2 & 0.048 & 8 \\
\hline
\end{tabular}

\section{VALIDATION OF THE PROPOSED MODEL}

T.L Saaty insisted the need to check for the consistency in the pairwise comparison matrix to eliminate the vagueness and error that might have crept in while judging and prioritizing the factors. [7]. 
This research work is validated by checking the consistency ration and by performing a sensitivity analysis. The following steps are followed to check the consistency ration.

First Step: From the Pairwise comparison Criteria matrix calculate the eigen vale and eigen vector using the equation 4 and 5

Second Step: The Eigen vector and eigen values are given in Table 16. Calculate the Value of Lambda Max from equation 6.

Third step: Calculate the Consistency Index from the Equation 7

Fourth Step: To calculate the final Consistency ration from equation 8 use the Random index values from Table 15. For this research work the R.I value is taken as 0.90

Calculate $W=\left[\begin{array}{c}W_{1} \\ W_{2} \\ \cdot \\ \cdot \\ \cdot \\ W_{n}\end{array}\right]$, where $W_{i}=\frac{\sum_{i=1}^{n} a_{i j}^{\prime}}{n}$

$W^{\prime}=A W=\left[\begin{array}{c}W_{1}^{\prime} \\ W_{2}^{\prime} \\ \cdot \\ \cdot \\ W_{n}^{\prime}\end{array}\right]$

And $\lambda_{\max }=\frac{1}{n}\left[\frac{W_{1}^{\prime}}{W_{1}}+\frac{W_{2}^{\prime}}{W_{2}}+\ldots \ldots \frac{W_{n}^{\prime}}{W_{n}}\right]$,

$W$ is the eigen vector, $W_{i}$ is the eigen value and $\lambda_{\max }$ corresponds to the largest eigen value of the pairwise comparison matrix.

The consistency index is given by

$$
\text { C.I }=\frac{\left(\lambda_{\max }-\mathrm{n}\right)}{(\mathrm{n}-1)}
$$

and $\mathrm{n}$ in this equation is the rank of the matrix.

Consistency Ratio C.R is given by

$$
\mathrm{C} . \mathrm{R}=\frac{C . I}{\mathrm{I} . \mathrm{R}}
$$

Random Index (R.I) and recommended consistency ratio values [9]

Table- V: Random Index (RI)

\begin{tabular}{|l|l|l|l|l|l|l|l|}
\hline Size(n) & 3 & 4 & 5 & 6 & 7 & 8 & 9 \\
\hline R.I & 0.58 & 0.90 & 1.12 & 1.24 & 1.32 & 1.41 & 1.45 \\
\hline
\end{tabular}

The matrix is consistent because the Consistency ratio obtained is 0.789 . which is less than 0.10 . For a Matrix to be consistent the value of C.R should be less than 0.10 [9]

Table- VI: Consistency ratio

\begin{tabular}{|l|l|l|l|l|l|l|}
\hline Factors & W & W' & $\lambda$ & $\begin{array}{l}\lambda \text { ma } \\
\text { x }\end{array}$ & C.I & C R \\
\cline { 1 - 4 } BAE & 0.3842 & 1.5914 & 4.142 & & & \\
\cline { 1 - 4 } EP & 0.1825 & 0.7737 & 4.2139 & \multirow{2}{*}{4.2139} & 0.0713 & \multirow{2}{*}{0.0801} \\
\cline { 1 - 4 } EAW & 0.2020 & 0.8570 & 4.242 & & & \\
\hline FC & 0.2312 & 0.9787 & 4.233 & & & \\
\hline
\end{tabular}

\section{SENSITIVITY ANALYSIS}

Sensitivity analysis are conducted to test the robustness of results obtained, As AHP is dependent on the human judgement therefore it is most likely that a small variation in expert opinion could induce variation in relative comparison of factors thereby impacting the final ranking [10]

Based on the Fig 4, Table 7 and Table 8, The top most ranks of the factors are stable for over a large variation of values from 0.1 to 0.9 . Most of the position of ranks have been maintained without any major deviation proving the robustness of results and dominating position of ranks.

\section{CONCLUSION AND FURTHER SCOPE}

The Global ranks and local ranks are given in Table 4. Among all the main factors Building energy Administration is the Top most Main factor that has high weightage followed by Energy policy. It means that BEA is the most important main factor that can impact the energy efficiency in a residential tower. Among the subfactors Energy Audit (BEA1) and Building Automation System (BEA2) are the top most subfactors that has high weightage. Energy education and awareness is top third subfactor. All these three subfactors do have high weightage and has the potential to impact building energy efficiency in a larger way.

This research has analyzed various factors effecting the energy efficiency of residential towers, a further extension of this research work can be a comparative analysis on different buildings in the same geographical rea. This comparative study could result in knowing the characteristics and behavior of buildings for energy efficiency. Similar study can be conducted for Commercial, educational and other HiRISE buildings for analysis of energy factors.

\section{MANAGERIAL IMPLICATIONS}

The proposed outcome of this research work can benefit energy managers of residential towers in planning building energy operations and Energy management. Building owners can prioritize retrofit projects giving more priority to high weightage Factors from Table 4 such as Building Automation system so that more Return on Investments could be achieved. Land owners and policy makers may make use of the outcome to propose an energy framework for energy efficiency and energy conservation in HiRISE Buildings.

\section{REFERENCES}

1. S. S. Chandel, A. Sharma and B. M. Marwaha, "Review of energy efficiency initiatives and regulations for residential buildings in India," Renewable and Sustainable Energy Reviews, Vol. 54, 2016 , 1443-1458.

2. P. Nejat, F. Jomehzadeh, M. M. Taheri, M. Gohari and M. Z. A Majid, "A global review of energy consumption, $\mathrm{CO} 2$ emissions and policy in the residential sector (with an overview of the top ten $\mathrm{CO} 2$ emitting countries)," Renewable and sustainable energy reviews, Vol. 43, 2015, 843-862

3. F. Patiño-Cambeiro, J. Armesto, G. Bastos, J. I. Prieto-López and F Patiño-Barbeito "Economic appraisal of energy efficiency renovations in tertiary buildings," Sustainable Cities and Society, 2019, 101503. 
4. G. Mylonas, D. Amaxilatis, L. Pocero, I. Markelis, J. Hofstaetter and P. Koulouris, "An educational IoT lab kit and tools for energy awareness in European schools," International Journal of Child-Computer Interaction, Vol. 20, 2019, 43-53.

5. E. Andersson, O. Arfwidsson, V. Bergstrand and P. Thollander, "A study of the comparability of energy audit program evaluations," Journal of cleaner production, Vol. 142, 2017, 2133-2139.

6. S. Ahmadi-Karvigh, B. Becerik-Gerber and L. Soibelman, "Intelligent adaptive automation: A framework for an activity-driven and user-centered building automation," Energy and Buildings, Vol. 188 , 2019, 184-199

7. T. L. Saaty, "A scaling method for priorities in hierarchical structures," Journal of mathematical psychology, Vol. 15(3), 1977, 234-281.

8. G. Zheng, N. Zhu, Z. Tian, Y. Chen and B. Sun, "Application of a trapezoidal fuzzy AHP method for work safety evaluation and early warning rating of hot and humid environments," Safety science, Vol 50(2), 2012, 228-239.

9. T. L. Saaty, "The analytic process: planning, priority setting, resources allocation," New York: McGraw, 1977.

10. S. Thanki, K. Govindan and J. Thakkar, "An investigation on lean-green implementation practices in Indian SMEs using analytical hierarchy process (AHP) approach," Journal of Cleaner Production, Vol. 135, 2016, 284-298.

\section{AUTHORS PROFILE}

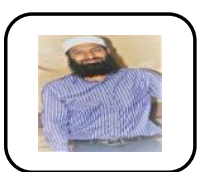

Syed Shuibul Qarnain is a Chartered Engineer(CEng) from Engineering Council U.K and Chartered Building service engineer from CIBSE, London. He is LEED accredited professional (LEED AP) from United States Green Building Council (USGBC). He obtained M.Tech in HVAC and MBA in Project Management. Currently he is a Research Scholar in the Department of Mechanical Engineering, Kalasalingam Academy of Research and Education, Krishnankoil, Tamilnadu, India. His research involvement is in the field of conservation of energy in Buildings using MCDM methods.

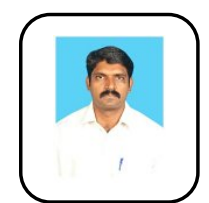

Dr.S.Muthuvel is an Associate Professor in the Department of Mechanical Engineering, Kalasalingam Academy of Research and Education, Krishnankoil, Tamilnadu, India. His current area of research includes phase change materials and energy conservation. He has published a number of papers in journal of national/international repute and presented a number of papers in various conferences/symposia in India and abroad. He is presently guiding a number of master/doctoral research scholars.

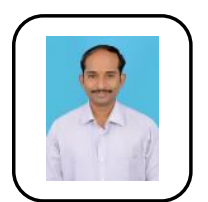

Dr.S.Bathrinath is an Associate Professor in the Department of Mechanical Engineering, Kalasalingam Academy of Research and Education, Krishnankoil, Tamilnadu, India. His current area of research includes multi-criteria decision making, scheduling \& optimization, soft computing and Artificial intelligence.
$\mathrm{He}$ has published a number of papers in journal of national/international repute and presented a number of papers in various conferences/symposia in India and abroad. He is presently guiding a number of master/doctoral research scholars. Dr.S.Bathrinath is the corresponding author and can be contacted at: bathri@gmail.com 
Table- VII. Global weights when BEA varies from 1 to 0.9

\begin{tabular}{|l|l|l|l|l|l|l|l|l|l|l|l|}
\hline & 0.1 & 0.2 & 0.3 & 0.384 & 0.4 & 0.5 & 0.6 & 0.7 & 0.8 & 0.9 \\
\hline BEA1 & 0.071 & 0.142 & 0.213 & 0.273 & 0.284 & 0.355 & 0.426 & 0.497 & 0.568 & 0.639 \\
\hline BEA2 & 0.029 & 0.058 & 0.087 & 0.111 & 0.116 & 0.145 & 0.174 & 0.203 & 0.232 & 0.261 \\
\hline EP1 & 0.128 & 0.114 & 0.099 & 0.087 & 0.085 & 0.071 & 0.057 & 0.043 & 0.028 & 0.014 \\
\hline EP2 & 0.071 & 0.063 & 0.056 & 0.049 & 0.048 & 0.040 & 0.032 & 0.024 & 0.016 & 0.008 \\
\hline EP3 & 0.068 & 0.060 & 0.053 & 0.046 & 0.045 & 0.038 & 0.030 & 0.023 & 0.015 & 0.008 \\
\hline EAW1 & 0.138 & 0.123 & 0.108 & 0.095 & 0.092 & 0.077 & 0.062 & 0.046 & 0.031 & 0.015 \\
\hline EAW2 & 0.094 & 0.083 & 0.073 & 0.064 & 0.062 & 0.052 & 0.042 & 0.031 & 0.021 & 0.010 \\
\hline EAW3 & 0.063 & 0.056 & 0.049 & 0.043 & 0.042 & 0.035 & 0.028 & 0.021 & 0.014 & 0.007 \\
\hline FC1 & 0.135 & 0.120 & 0.105 & 0.093 & 0.090 & 0.075 & 0.060 & 0.045 & 0.030 & 0.015 \\
\hline FC2 & 0.068 & 0.060 & 0.053 & 0.046 & 0.045 & 0.038 & 0.030 & 0.023 & 0.015 & 0.008 \\
\hline FC3 & 0.065 & 0.058 & 0.051 & 0.045 & 0.043 & 0.036 & 0.029 & 0.022 & 0.014 & 0.007 \\
\hline FC4 & 0.070 & 0.062 & 0.054 & 0.048 & 0.047 & 0.039 & 0.031 & 0.023 & 0.016 & 0.008 \\
\hline
\end{tabular}

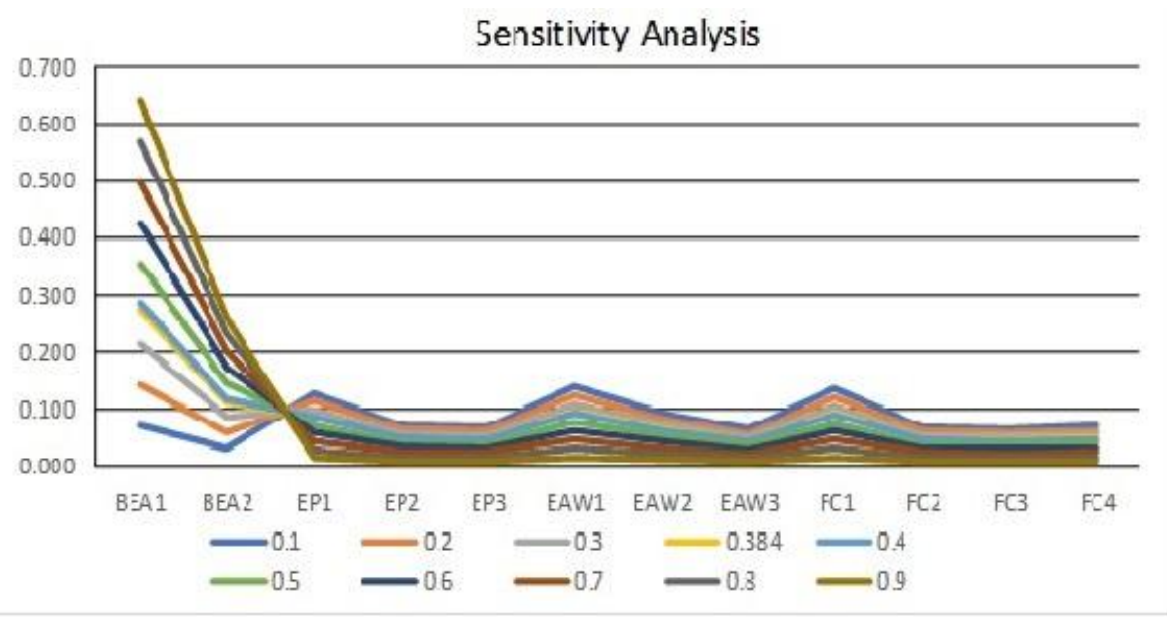

Fig. 4. Sensitivity analysis

Table- VIII. Ranks with BEA varying from 0.1 to 0.9

\begin{tabular}{|l|l|l|l|l|l|l|l|l|l|l|}
\hline & 0.1 & 0.2 & 0.3 & 0.384 & 0.4 & 0.5 & 0.6 & 0.7 & 0.8 & 0.9 \\
\hline BEA1 & 6 & 1 & 1 & 1 & 1 & 1 & 1 & 1 & 1 & 1 \\
\hline BEA2 & 12 & 10 & 5 & 2 & 2 & 2 & 2 & 2 & 2 & 2 \\
\hline EP1 & 3 & 4 & 4 & 5 & 5 & 5 & 5 & 5 & 5 & 5 \\
\hline EP2 & 5 & 6 & 7 & 7 & 7 & 7 & 7 & 7 & 7 & 7 \\
\hline EP3 & 9 & 9 & 10 & 10 & 10 & 10 & 10 & 10 & 10 & 10 \\
\hline EAW1 & 1 & 2 & 2 & 3 & 3 & 3 & 3 & 3 & 3 & 3 \\
\hline EAW2 & 4 & 5 & 6 & 6 & 6 & 6 & 6 & 6 & 6 & 6 \\
\hline EAW3 & 11 & 12 & 12 & 12 & 12 & 12 & 12 & 12 & 12 & 12 \\
\hline FC1 & 2 & 3 & 3 & 4 & 4 & 4 & 4 & 4 & 4 & 4 \\
\hline FC2 & 8 & 8 & 9 & 9 & 9 & 9 & 9 & 9 & 9 & 9 \\
\hline FC3 & 10 & 11 & 11 & 11 & 11 & 11 & 11 & 11 & 11 & 11 \\
\hline FC4 & 7 & 7 & 8 & 8 & 8 & 8 & 8 & 8 & 8 & 8 \\
\hline
\end{tabular}

